\title{
¿PUEDEN CONSTITUIR TODAS LAS DENOMINADAS EXPRESIONES DE ODIO UN LÍMITE INFRANQUEABLE A LA LIBERTAD DE EXPRESIÓN?
}

\author{
Jorge Alguacil González-Aurioles \\ doi: 10.18543/ed-64(1)-2016pp309-327
}

\begin{abstract}
Sumario: 1. LA LIBERTAD DE EXPRESIÓN EN EL SISTEMA DE DERECHOS FUNDAMENTALES. 2. SOBRE LOS LÍMITES A LA LIBERTAD DE EXPRESIÓN. 2.1. Libertad de expresión y manifestaciones de odio. 2.2. ¿Del límite de la apología de los comportamientos delictivos a la extensión de la criminalización de las expresiones de odio? 3. DEMOCRACIA Y LIBERTAD DE EXPRESIÓN: SOBRE LAS GARANTÍAS DE ESTA LIBERTAD. 3.1. Estados Unidos de América del Norte. a) Libertad de expresión: teoría y realidad constitucional. b) Jurisprudencia favorable a extender las garantías de la libertad de expresión. 3.2. Alemania. a) Libertad de expresión: teoría y realidad constitucional. b) Jurisprudencia favorable a extender las garantías de la libertad de expresión. 4. A MODO DE CONCLUSIONES.
\end{abstract}

El juez de la Audiencia Nacional Ismael Moreno decretó el pasado mes de febrero el encarcelamiento sin fianza de los titiriteros que representaron en Madrid y, previamente en Granada, la obra La bruja y Don Cristobal. Parece fuera de duda el evidente error de programar esa obra para un público infantil como hizo el Ayuntamiento de Madrid, que la consideró recomendable para todos los públicos. Pero cabe plantearse si estamos ante un hecho presuntamente delictivo o ante el ejercicio, por muy desagradable u ofensivo que resulte para algunos o muchos, de la libertad de expresión. El Tribunal Europeo de Derechos Humanos ha manifestado que la libertad de expresión 
también ampara «aquéllas (manifestaciones) que chocan, inquietan u ofenden al Estado o a una fracción cualquiera de la población» ${ }^{1}$.

La polémica planteada no es nueva, y los conflictos generados en torno a ella a lo largo de nuestra historia constitucional son numerosos; a las dudas que genera el anterior caso, podemos añadir otras preguntas. Por ejemplo, ¿puede ser condenado un ex sacerdote católico por haber incitado en un discurso público al odio contra ciertos grupos que entiende que ponen en riesgo la seguridad del país? ¿Cabe condenar a un pacifista por portar una pancarta en que se lea: Todos los soldados son asesinos? ¿Y si es un catedrático de instituto el que escribe tales palabras como protesta a una exposición sobre las fuerzas armadas que va a realizarse en el instituto en que imparte docencia?

La duda que nos asalta a los juristas y ciudadanos en general es también evidente: ¿nos encontramos ante manifestaciones susceptibles todas ellas de ser subsumidas en supuestos de hecho previstos en el Código Penal? ¿O pueden por el contrario ser considerados libre ejercicio de la libertad de expresión y en consecuencia ser amparados por este derecho fundamental? Las respuestas no son fáciles, aunque los supuestos, reales, tuvieron contestación por tribunales de justicia. No obstante, ello quizá permita adentrarnos, aunque sea simplemente para reflejar más incertidumbres que certezas, en el complejo campo de uno de los conocidos límites a la libertad de expresión, la manifestación de expresiones de odio. Una primera aproximación al concepto de la libertad de expresión (1) nos permitirá centrarnos en el examen del mencionado límite (2); para, a continuación, exponer las garantías de esta libertad central de nuestro vigente constitucionalismo. Procuraremos alcanzar ciertas conclusiones que quizá puedan orientar la mejor salvaguardia de la libertad en una democracia avanzada como la que proclama la Constitución de 1978 (4).

\section{LA LIBERTAD DE EXPRESIÓN EN EL SISTEMA DE DERECHOS FUNDAMENTALES}

Como es por todos conocido, la existencia de una opinión pública libre es condición necesaria para el correcto funcionamiento de la democracia. Por eso posee una importante dimensión institucional: la existencia efectiva de expresión e información libres es objetivamente valiosa para el conjunto de la sociedad.

A partir de tal premisa, bien cabe considerar a esta libertad, como hace el Profesor Sánchez, como la «piedra de toque de un régimen político, de todo régimen político. Su existencia o ausencia, sus límites legales, su uso en for-

${ }^{1}$ Asunto Handyside c Reino Unido de 7/12/1976 y mucho más reciente, caso Otegui c España, 15/03/2011. 
ma de libertad de información, su abuso, su entendimiento, su regulación, su alcance, su interpretación por los ciudadanos, por los medios de comunicación, por la clase política y por el gobierno, sus pretendidas bases teóricas, revelan cada uno de ellos y todos globalmente considerados, la naturaleza más o menos liberal y más o menos democrática de la estructura de poder vigente en una sociedad en un momento determinado ${ }^{2}$. La libertad de expresión, efectivamente, es matriz de otras libertades, y singularmente de la que se ha denominado la libertad básica de la democracia, la libre e igual participación política. La libertad de expresión ha hecho posible la propia evolución del constitucionalismo (vuelve a decirlo el Profesor Sánchez con particular acierto: "posibilitó el paso de gobiernos de base elitista, elegidos por reducísimos sectores de la población adulta, a los modernos gobiernos constitucionales que cuentan con el apoyo de millones de votantes $\rangle^{3}$ ) y permite sustentar nuestras modernas democracias pluralistas «en el conflicto pacífico entre los gobiernos mayoritarios y las minorías extraparlamentarias $»^{4}$.

Por otro lado, ya nos recordó Hesse cómo la democracia precisa de la libre formación de la opinión pública y de cómo la libertad de expresión permite la gestación de tal opinión pública ${ }^{5}$. La conexión de la libertad de expresión y de su versión democrática, el derecho a recibir información, con el mejor desenvolvimiento de nuestro régimen constitucional, es evidente: «la compleja democracia de hoy sin ciudadanos informados es una contradicción en la medida en que la información es poder $-\mathrm{y}$ actúa como contrapoder» ${ }^{6}$. Ahora bien, los constitucionalistas nos hemos cansado de afirmar que ningún derecho es ilimitado, y la libertad de expresión no es una excepción. La delimitación de los derechos sigue siendo una de las cuestiones más polémicas de nuestra disciplina científica, y alcanza en relación con los límites a la libertad de expresión una de sus más altas cotas de conflictividad. A analizar los límites que históricamente se han impuesto a la libertad de expresión (2), pero también a las posibilidades de garantía de tal libertad (3), dedicaremos las siguientes páginas.

\section{SOBRE LOS LÍMITES A LA LIBERTAD DE EXPRESIÓN}

\subsection{Libertad de expresión y manifestaciones de odio}

Como observa Díez-Picazo, el valor o bien jurídico protegido por la libertad de expresión e información «es la existencia de una opinión pública, la

2 SÁnchez González, S., La libertad de expresión, Madrid: Marcial Pons, 1992, p. 14.

3 SÁnchez GonzÁlez, S., La libertad de expresión, op. cit, p. 67.

4 SÁnchez GonzÁlez, S., La libertad de expresión, op. cit, p. 67.

${ }_{5}^{5}$ Hesse, K., GrundzUge des Verfassungsrechts der Bundesrepublick Deutschland, 18 Auflage, Heilderberg: Müller, 1991, p. 63.

${ }^{6}$ SÁnchez González, S., La libertad de expresión, op. cit, p. 121. 
cual es, a su vez, una condición necesaria para el correcto funcionamiento de la democracia (STC 6/1981, 20/1990, 85/1992, etc)» ${ }^{7}$. La dimensión institucional de tal libertad hace que su existencia efectiva sea objetivamente valiosa para el conjunto de la sociedad.

Ahora bien, existen límites; el propio artículo 20 CE los prevé: se encuentran en los demás derechos e intereses constitucionalmente reconocidos, especialmente los de la vida privada y los orientados a la protección de la juventud. El Convenio Europeo de Derechos Humanos ha previsto igualmente limitaciones a tal libertad siempre que concurran tres condiciones: A) que la finalidad sea salvaguardar ciertos bienes jurídicos (seguridad nacional, protección de la moral, reputación de las personas, etc) B) que se establezca por ley y C) que se trate de «medidas necesarias en una sociedad democrática». La fijación de estos límites no resulta sencilla, la generalidad de los mismos impide cualquier automatismo, y debe ser el legislador el que realice la no siempre fácil tarea de ponderación de los diferentes valores que entren en colisión. La tarea de legislar consiste precisamente en esto ${ }^{8}$.

No obstante, la normatividad de la Constitución, conquista del constitucionalismo posterior a la II Guerra Mundial, parece que debe mover igualmente al Tribunal Constitucional a controlar tal actividad legislativa: un control ciertamente de límites que el legislador no puede traspasar en tal tarea de ponderación. Por lo demás, como es por todos conocido, el legislador, merced al artículo 53.1 CE, pasa de ser un «enemigo potencial» de la Constitución y de los derechos fundamentales a ser el poder público indispensable que necesitan para desplegar plena eficacia (también al limitarlos, haciéndolo solo en su justa medida), su relación con la Carta Magna y con los derechos fundamentales adquiere una nueva dimensión: la cooperativa. Ambos, derechos y ley, deben cooperar para asegurar la fuerza normativa de aquéllos.

Cabe pues realizar un juicio al legislador sobre su mejor o más perfecta contribución como poder público a la efectividad de los derechos fundamentales y en concreto a la efectividad de la libertad de expresión. Entre las muchas colisiones típicas en materia de libertad de expresión e información nos centraremos en una especialmente controvertida y que en la actualidad ha ido ganando protagonismo: la colisión de la libertad de expresión con las denominadas expresiones de odio, toda vez que éstas puedan llegar a constituir apología del delito.

7 Díez-PiCAzo, L.M., Sistema de Derechos Fundamentales, Madrid: Thomson Cívitas, 2003, p. 281.

8 SÁnCHEZ GonzÁlez, S., «De la imponderable ponderación y otras artes del Tribunal Constitucional», Teoría y Realidad Constitucional n. ${ }^{\circ}$ 12-13, 2 semestre 2003-1 semestre 2004, p. 378. 
Como es conocido, apología significa discurso de palabra o por escrito, en defensa o alabanza de alguien o algo; en este caso, de la comisión de un delito. Y ciertamente, parece que dicho discurso encierra un límite claro a la libertad de expresión. El Derecho constitucional español no dispone de forma expresa este límite, ni la carta Magna, ni ley orgánica alguna que desarrolle los derechos fundamentales contenidos en aquélla, dice nada al respecto. El artículo 20.4 de la Constitución española impone únicamente el límite genérico del respeto a los derechos reconocidos en el Título I, a los preceptos de las leyes que los desarrollen, y especialmente a la libertad de expresión, al derecho al honor, a la intimidad, a la propia imagen y a la protección de la juventud y la infancia. El apartado 7 del artículo 7 de la Ley Orgánica 1/1982, de 5 de mayo, de protección civil del derecho al honor, a la intimidad personal y familiar y a la propia imagen, dispone como intromisión ilegítima en la protección del honor «la imputación de hechos o la manifestación de juicios de valor a través de acciones o expresiones que de cualquier modo lesionen la dignidad de otra persona, menoscabando su fama o atentando contra su propia estimación». Hemos de acudir pues al Derecho Penal para encontrar este límite configurado como delito: el Código Penal español estipula no sólo la provocación como una posible forma de participación en el delito (artículo 18 del Código Penal, CP en adelante), además puede constituir un tipo delictivo en sí mismo: así ocurre con la provocación a cometer actos de racismo (artículo $510 \mathrm{CP}$ ), de terrorismo (artículo $578 \mathrm{CP}$ ) o a la secesión (artículo $585 \mathrm{CP}$ ). Por lo demás, existe el delito de injurias (artículo $208 \mathrm{CP}$ ) y de calumnias (artículo $205 \mathrm{CP}$ ).

El Derecho Internacional de los derechos humanos tampoco ha reconocido de una forma expresa esta frontera a la libertad de expresión, con una excepción: lo preceptuado en la Convención Americana de los Derechos Humanos. El artículo 19 de la Declaración Universal de Derechos Humanos no establece límites expresos a la libertad de expresión, y el artículo 10 de la Carta Europea de Derechos Humanos se limita a fijar los consabidos límites genéricos a esta libertad: puede ser limitada siempre y cuando tales lindes constituyan medidas necesarias, en una sociedad democrática, para la seguridad nacional, la integridad territorial o la seguridad pública, la defensa del orden y la prevención del delito, la protección de la salud o de la moral, la protección de la reputación o de los derechos ajenos, para impedir la divulgación de informaciones confidenciales o para garantizar la autoridad y la imparcialidad del poder judicial. La Convención Americana de Derechos Humanos, redactada en noviembre de 1969, establece por primera vez de forma clara este límite. Su artículo 13 establece: queda excluida del amparo de esta libertad «toda propaganda en favor de la guerra y toda apología del odio nacional, racial o religioso que constituyan incitaciones a la violencia o cualquier otra acción ilegal similar contra cualquier persona o grupo de personas, 
por ningún motivo, inclusive los de raza, color, religión, idioma u origen nacional».

Parece así que el límite puede consistir en la incitación a la violencia, pues ello entraña simple y llanamente la comisión de un delito. El problema que a renglón seguido se plantea es definir qué es incitación a la violencia, y diferenciarlo de manifestaciones de odio que no necesariamente persigan la incitación a la violencia, sino simplemente la libre expresión de opiniones. El reto, en definitiva, puede consistir en tratar de diferenciar la apología de comportamientos delictivos de ciertas manifestaciones de las denominadas expresiones de odio que quizá pudieran encuadrarse dentro de los límites de la garantía de la libertad de expresión ${ }^{9}$.

\section{2. ¿Del límite de la apología de los comportamientos delictivos a la extensión de la criminalización de las expresiones de odio?}

Alerta Díez-Picazo de cómo la «represión de expresiones de odio, por muy buenas razones que puedan justificarla, entraña siempre el riesgo de acallar las opiniones que no son «políticamente correctas» y por tanto privar de espacio a los heterodoxos y disidentes ${ }^{10}$; y no debemos olvidar que la libertad de expresión no existe sólo para proteger las ideas u opiniones comúnmente establecidas, sino también aquellas minoritarias que chocan y perturban. Las denominadas «expresiones de odio» o «hate speech» agrupan una serie de supuestos como la Negación del Holocausto del Pueblo Judío, mensajes racistas y xenófobos, manifestaciones de sexismo y homofobia; pero también simples manifestaciones provocativas incitando al odio o al desprecio hacia determinados colectivos. El problema reside en hacer que todas las expresiones de odio, sean cuales sean, puedan encontrarse siempre subsumidas en algún supuesto de hecho contemplado por el Código Penal; porque entonces podríamos encontrarnos ante un riesgo mayor, denunciado por ciertos penalistas: legitimar o incluso potenciar el conocido tránsito del denominado Derecho penal del ciudadano al Derecho penal del enemigo.

Günter Jakobs refleja la diferencia entre ambas formas de concebir el Derecho penal de forma muy clara: «el Derecho penal del ciudadano mantiene la vigencia de la norma, el Derecho penal del enemigo (en sentido amplio, incluyendo las medidas de seguridad) combate peligros...no se trata en primera línea de la compensación de un daño a la vigencia de la norma, sino de

${ }^{9}$ Un estudio detallado y riguroso puede encontrarse en MARTín HERRERA, D., «Libertad de expresión: ¿derecho ilimitado según el TEDH? Del discurso de odio al crimen de odio», Estudios de Deusto, vol. 62/2 Julio-diciembre, 2014, pp. 15-40.

${ }^{10}$ DíEz-Picazo, L.M., Sistema de derechos fundamentales, Madrid: Thomson, 2003, pp. 296, 297. 
la eliminación de un peligro: la punibilidad se adelanta un gran trecho hacia el ámbito de la preparación, y la pena se dirige hacia el aseguramiento frente a hechos futuros, no a la sanción de hechos cometidos (...) en el Derecho penal del ciudadano, la función manifiesta de la pena es la contradicción, en el Derecho penal del enemigo la eliminación de un peligro» ${ }^{11}$. El incremento injustificado de infracciones y sanciones es también característico de este Derecho penal del enemigo, y sobre todo la regulación de ciertos tipos penales en los que se criminalizan meros actos de comunicación de la desafección hacia instituciones o símbolos. El artículo 543 del vigente Código Penal prevé, por ejemplo, que «las ofensas o ultrajes de palabra, por escrito o de hecho a España, a sus Comunidades Autónomas o a sus símbolos o emblemas, efectuados con publicidad, se castigarán con la pena de multa de siete a doce meses». No se exige una acción concreta, eventualmente violenta, contra personas o bienes que simbolicen o encarnen tales símbolos o emblemas. Se penaliza el simple riesgo o peligro de que ello pudiera llegar a suceder. La represión del desafecto, en este caso, parece que vulnera los límites constitucionales. Precisamente por esa dimensión institucional de la que goza la libertad de expresión; su íntima conexión con la democracia y con el pluralismo político y social mueven a colocarla en una posición preferente que le otorgue particulares garantías; incluso frente a ciertas expresiones de odio.

El Tribunal Constitucional español ha manifestado de forma clara la necesidad de colocar a la libertad de expresión «en una posición preferente y objeto de especial protección» (STC 101/2003, de 2 de junio, FJ3); configura en definitiva la libertad de expresión como «un ámbito exento de coacción lo suficientemente generoso como para que pueda desenvolverse sin angosturas, esto es, sin timidez y sin temor» (STC 9/2007, de 15 de enero, FJ4). El Tribunal Europeo de Derechos Humanos ha sido aún más claro: ha insistido en la protección de las expresiones que «ofenden, hieren o molestan» como exigencia del «pluralismo, la tolerancia y la mentalidad amplia, sin los cuales no hay sociedad democrática» (STEDH Thorgeir Thorgeirson contra Islandia, de 25 de junio de 1992).

En cualquier caso, no se oculta que nos encontramos en supuestos límites, y la mayor o menor protección de esta libertad depende en muchos casos del concreto régimen constitucional. No obstante, como procuraremos demostrar, incluso en los regímenes constitucionales que en determinados momentos históricos han mostrado un mayor desafecto hacia las opiniones disidentes, existe también cierta jurisprudencia que ha ido mostrando la conveniencia de otorgar mayores garantías a la libertad de expresión frente a eventuales expresiones de odio o especialmente polémicas.

11 Jakobs, G.; Canció Meliá, M., Derecho penal de enemigo, Thomson. Cívitas, Madrid, 2003, pp. 33, 40 y 55. 


\section{DEMOCRACIA Y LIBERTAD DE EXPRESIÓN: SOBRE LAS GARANTÍAS DE ESTA LIBERTAD.}

Son seguramente los regímenes constitucionales de Estados Unidos de América del Norte y de Alemania los que han mantenido en algún momento histórico una mayor beligerancia hacia la posibilidad de expresar ideas $\mathrm{u}$ opiniones que pudieran considerarse atentatorias contra el propio orden constitucional vigente. Es cierto que existe una profunda divergencia en la concepción de la libertad de expresión por parte de ambos países y regímenes constitucionales, en realidad una contraposición entre un modelo característico norteamericano y otro que podríamos denominar europeo. Tal divergencia quizá pudiera evidenciarse en la propia contraposición entre el artículo 10 del Convenio Europeo de Derechos Humanos y la primera enmienda de la Constitución Norteamericana. Frente a los límites previos legales del texto europeo, la Primera enmienda defiende la libertad ilimitada de palabra-discurso en un mercado libre de ideas desde la neutralidad del Estado-Gobierno. El orden constitucional europeo defiende la intervención del Estado para garantizar a través de las leyes el derecho a la información veraz y plural, respetuoso con los derechos fundamentales de las personas que constituye límites legales a la libertad de expresión ${ }^{12}$.

Ahora bien, razones históricas explican que ambas formas de concebir el orden constitucional hayan podido desplegar una legislación y jurisprudencia atentatoria contra la libertad de expresión, contraria eventualmente a la propia noción de democracia. Ambas realidades, en fin, podrían verse en realidad ciertamente conectadas; lo vuelve a resaltar el Profesor Sánchez: el «temor norteamericano al comunismo y a las ideas disolventes tiene su pariente más cercano en la democracia militante-wehrhafte Demokratie-alemana» ${ }^{13}$. Sin embargo, decíamos antes cómo incluso en estos regímenes constitucionales podemos encontrar también cierta jurisprudencia que otorga una especial garantía a la libertad de expresión; y ello al comprenderla como derecho y valor especialmente ligado al del pluralismo y así al de la propia existencia de la democracia.

Dos casos que dan respuesta a los interrogantes mostrados en el comienzo de este artículo pueden ilustrar a nuestros efectos las posibilidades en la extensión de la garantía de la libertad de expresión. Y ambos traen causa precisamente de los dos regímenes constitucionales comentados, el americano y el alemán. La eventual extensión de la libertad de expresión, garantía de exis-

${ }^{12}$ Hoffmann-Riem, H., «Libertad de comunicación y de medios», Benda, E.; MaIhofer, W.; Vogel, H.; Hesse, K.; Heyde, W., Manual de Derecho constitucional. Madrid. Barcelona. Marcial Pons, 2001, pp. 145 y ss.

13 SÁnchez GonzÁlez, S., La libertad de expresión, op. cit, p. 100. 
tencia de un régimen constitucional, cobra carta de naturaleza; ambos casos cobran así un especial interés. Al análisis, necesariamente resumido, de la forma de concebir la naturaleza de este derecho y de otorgarle protección, le seguirá el estudio del caso específico que permite extender las garantías de esta libertad.

\subsection{Estados Unidos de América del Norte}

\section{a) La libertad de expresión: teoría y realidad constitucional}

Como es conocido, la enmienda primera a la Constitución de Estados Unidos consagra la libertad de religión y la libertad de expresión: prohíbe la aprobación de ley alguna que pueda establecer una religión oficial, o que prohíba el libre ejercicio de la misma o que coarte la libertad de palabra o de prensa; consagra el derecho del pueblo a reunirse pacíficamente y a solicitar del Gobierno la reparación de agravios. Esta primera enmienda fue presentada a los Estados para su ratificación el 25 de septiembre de 1789, y fue aprobada el 15 de diciembre de 1791. Ahora bien, las limitaciones a la libertad de expresión en los Estados Unidos han sido reconocidas desde el primer momento: la Corte Suprema de dicho país así lo ha hecho en una jurisprudencia más o menos constante. Aquellos discursos catalogados como provocativos, declaraciones falsas de hechos, obscenidad, pornografía infantil o amenazas han sido expresamente sacados de protección de esta primera enmienda; en el caso Chaplinsky v. New Hampshire de 1942 la Corte sostuvo que las denominadas «palabras de pelea...que por el hecho de ser pronunciadas inflingen lesión o tienden a incitar un rompimiento de la paz inmediato» no están amparadas. Existen también restricciones basadas en la especial capacidad de dirección de que dispone el Gobierno sobre Fuerzas Armadas, presos, etc.

En cualquier caso, se han producido casos flagrantes de vulneración de las garantías de esta primera enmienda: en 1912 la feminista Margaret Sanger fue arrestada por impartir una conferencia sobre el control de natalidad, el ingreso de Estados Unidos en la Primera Guerra Mundial provocó protestas por ciudadanos que fueron encarcelados; en fin, a comienzos de los años 20 del siglo pasado muchos Estados ilegalizaron la exposición de banderas negras, de símbolos del comunismo o de la anarquía.

Y no podemos olvidar, por último, el periodo quizá más oscuro del régimen constitucional norteamericano, el comprendido entre 1950 y 1956 en el que el senador McCarthy desencadenó un extendido proceso de delaciones, acusaciones infundadas, denuncias, interrogatorios, procesos irregulares y listas negras contra personas sospechosas de ser comunistas. Al margen de que defender de forma pacífica una determinada idea o ideología parece que nunca debiera ser considerado un delito en una democracia abierta y pluralis- 
ta, importa destacar que el proceso desencadenado olvidaba también el derecho fundamental de presunción de inocencia; $y$ ante cualquier denuncia ante el Comité del Senado, presidido por el senador McCarthy, aplicaba la presunción de culpabilidad, era el acusado el que tenía que demostrar su supuesta inocencia. Es cierto que no podemos olvidar que nos encontramos en los años más duros e inestables de la denominada «Guerra Fría», pero tampoco debemos minusvalorar las resistencias a esta forma de obrar por dramaturgos como Arthur Miller (en 1953 se representó la obra «Las brujas de Salem») o periodistas como Edwrd R. Murrow (con su programa en televisión See it now iniciado el 9 de marzo de 1954).

b) Jurisprudencia favorable a extender las garantías de la libertad de expresión

Destaca el caso Terminello v. Ciudad de Chicago de 1949 en el que la Corte Suprema de los Estados Unidos levanta la sanción que pesaba sobre el antiguo sacerdote Teminello y declara inconstitucional la ordenanza de la ciudad de Chicago que castigaba aquellos discursos que incitaran al odio, invitaran a la disputa o crearan situaciones de desorden público por ser contraria a la primera y decimocuarta enmienda. Este ex sacerdote pronunció un discurso a un grupo de cristianos veteranos de América en el que criticó a varios grupos raciales y realizó un número importante de comentarios hirientes y provocativos; alertó sobre la amenaza del comunismo en Rusia, lugar en el que entre ocho y quince millones de personas habían sido asesinadas por sus propios compatriotas, y millones más a lo largo del este de Europa; destacó que los comunistas de Estados Unidos querían para ellos eso mismo: están planeando hacer una nueva Rusia. Incluso llegó a sugerir en su discurso que alguien le había recordado un plan para esterilizar a todos los comunistas, todos ellos por supuesto no cristianos. Por último, conminó al auditorio a ser como los Apóstoles que combatan la lacra del comunismo.

En el auditorio había unas 800 personas y una multitud fuera del mismo de unas mil personas protestando por el discurso. La policía de Chicago no pudo mantener el orden y Terminello tuvo que pagar una multa de 100 dólares en aplicación de la mencionada ordenanza de la ciudad de Chicago. La Corte de Apelación de Illinois y la Suprema Corte de Illinois confirmaron la procedencia de la multa. La Corte Suprema, por el contrario, en esta conocida sentencia, liberó al ciudadano Terminello del pago de la mencionada multa.

William O Douglas fue el juez que actuó como ponente de la sentencia. Explicó cómo el sentido de la libertad de expresión es la invitación a la disputa, incluso si eso incita a la gente al odio; los comentarios provocativos e hirientes pueden incluso ser contemplados de forma positiva. La vitalidad de 
las instituciones civiles y políticas depende de la libre discusión. Citando lo que manifestó el Juez Hughes en el caso De Honge\&Oregon U.S. 35, sólo a través del libre debate y del libre intercambio de ideas y opiniones puede asegurarse que el Gobierno mantenga su responsabilidad frente la voluntad del pueblo y puede garantizarse la pacífica alternancia política. Por lo demás, recalca cómo la vitalidad de las instituciones civiles y políticas en nuestra sociedad dependen de la libre discusión. El derecho a hablar libremente y promover la diversidad de ideas y programas es en consecuencia una de las diferencias básicas que nos diferencia a las democracias de los sistemas totalitarios.

El juez Douglas era consciente que la libertad de expresión tiene sus límites. Ciertamente existen muchas declaraciones y manifestaciones políticas que son provocativas y desafiantes. Pero en su opinión, sólo cabe prohibir aquellas en las que las palabras usadas puedan crear un daño real y presente (clear and present danger); el juez consideró en el casco concreto que no se daban las circunstancias que podrían justificar la existencia de tal daño real y presente.

Sabido es que la sentencia tuvo varios disidentes, y que quizá el más duro fue el que protagonizó el juez Jackson. En su opinión, la Primera Enmienda protege la libre expresión de ideas, pero no de forma absoluta, en todas las circunstancias, máxime ante el perjuicio que tal libertad de expresión pueda causar en el mantenimiento del orden público. El escenario caótico y violento que produjo el discurso de Terminello, en su opinión, podía desencadenar un conflicto entre fascismo y comunismo que podía ser usado por grupos de ambos bandos que hicieran uso de métodos violentos para extender su ideología; tales bandos se configuraban en un claro peligro para la democracia. En definitiva, opina que el tribunal había ido demasiado lejos en las tesis defendidas. Su voto particular terminaba de forma categórica: la elección no es entre orden y libertad, sino entre libertad con orden y anarquía sin ninguna de ellas.

\subsection{Alemania}

a) La libertad de expresión: teoría y realidad constitucional

Es cierto que el artículo 5 de la Ley Fundamental de Bonn reconoce la libertad de expresión: proclama el derecho que tienen todos a expresar y difundir libremente la propia opinión oralmente, por escrito y con recurso a imágenes, aun cuando ya fija como límites expresos las leyes generales, las disposiciones legales para proteger a la juventud y el derecho al honor personal. Pero no podemos olvidar tampoco cómo el artículo 18 de la misma Ley Fundamental de Bonn sanciona con la pérdida de ciertos derechos, entre ellos 
el de la libertad de expresión, siempre que se abuse de ellos...para combatir el orden básico democrático libre»; y que el artículo 21 declara inconstitucionales aquellos partidos políticos que «por razón de sus fines o de la conducta de sus miembros pretendan causar daño o abolir el orden básico democrático libre o poner en peligro la existencia de la República Federal Alemana». La «democracia militante» expresamente asumida por este constitucionalismo da cobertura a severas limitaciones a esta libertad. El rechazo al extremismo de derechas y sobre todo a tendencias neonazis constituyó en la creación del nuevo orden constitucional alemán una obsesión evidente ${ }^{14}$.

b) Jurisprudencia favorable a extender las garantías de la libertad de expresión

El Tribunal Constitucional Federal alemán (Bundesverfassungsgericht) ha desarrollado a partir de los años ochenta del pasado siglo unas especiales garantías a la libertad de expresión; cabe citar al efecto tres importantes sentencias: la temprana resolución de 7 de diciembre de 1976 (BVerfGE 43, 130), la sentencia de 26 de junio de 1990 (BVerfGE 28, 236) y la más reciente la resolución alle Soldaten sind mörder de 10 de octubre de 1995 (BVerfGE 93, 266); quizá en esta resolución se explica de una forma más clara esta específica relación. No cabe ocultar, en cualquier caso, que estas sentencias fueron muy polémicas y tuvieron votos enfrentados; en la segunda, incluso, se produce una división en el tribunal que causa la no estimación del recurso.

La resolución del Bundesverfassungsgericht de 10 de octubre de 1995 (BVerfGE 93, 266) trae causa de cuatro recursos de amparo acumulados; el elemento común que los caracteriza es el haber empleado la conocida frase de Tucholsky «alle Soldaten sind Mörder» (todos los soldados son asesinos) frente a la autoridad militar; quizá sea oportuno recordarlos.

El primer recurso lo plantea un estudiante de 30 años que en una maniobras militares de la OTAN que tuvieron lugar en Francia portó una sábana en la que se podía leer «A Soldier is a Mörder». El teniente responsable de las maniobras denunció al estudiante por ofensa a las fuerzas armadas y el tribunal de primera instancia le condenó a pagar una multa. Este tribunal realiza una específica interpretación de lo escrito en la sábana: la traducción literal («un soldado es un asesinato») no tiene sentido, por lo que sólo se puede comprender como un soldado es un asesino. Esto supone una intromisión antijurídica en el honor del teniente que no puede entenderse justificada por la genérica libertad de expresión. El tribunal de apelación del Land acepta la

${ }^{14}$ Denninger, E., «Democracia militante y defensa de la Constitución», Benda, E.; Maihofer, W.; Vogel, H.; Hesse, K.; Heyde, W., op. cit, pp. 445 y ss. 
interpretación literal de la palabra mord como muerte y, por consiguiente la doble dimensión del soldado como víctima y verdugo; en cualquier caso, el término empleado sigue constituyendo una ofensa contra el honor del teniente. El Tribunal Supremo de Baviera confirma la sentencia. Sin embargo, el estudiante pacifista acude al Tribunal Constitucional Federal en amparo alegando la vulneración de los artículos 5 y 103 LF. Con la expresión escrita quería incidir en el estado de opinión sobre las fuerzas armadas; la formulación estaba destinada al foro público, y en tal sentido entendía que debía encontrar protección constitucional.

El segundo recurso trae causa de un escrito de un catedrático de instituto de formación profesional que reacciona frente a una exposición sobre las fuerzas armadas que se iba a realizar en el instituto en el que impartía docencia. En este escrito, que comienza preguntándose si los soldados son potenciales asesinos, anima a la resistencia al militarismo pues éste en su opinión mata. Un soldado inicia un procedimiento contra el catedrático y el tribunal de primera instancia le condena por ofensa; entiende que la palabra asesino la ha empleado en un sentido jurídico; nos encontramos ante una sencilla difamación. El tribunal de apelación confirma la sentencia y lo propio hace el Tribunal Supremo del Land. El recurso de amparo se fundamenta de nuevo en la violación de los artículos 5.1 y 103.2 LF. Además de entender que sus expresiones sólo querían generar un estado de opinión e incidir así en el foro público, alerta sobre la indeterminación del término ofensa.

El tercer recurrente había escrito una carta al director en un periódico de información general en el que se solidarizaba con un doctor que había sido absuelto en un proceso relacionado con las fuerzas armadas. En este escrito vuelve a repetir la famosa frase de Tucholsky, alle Soldaten sind Mörder, en su opinión, de actualidad. El tribunal de primera instancia lo condena por difamación a una pena pecuniaria. El doctor con el que se solidariza profirió esta frase a un soldado concreto y le dijo que también él era un asesino; esto es prueba suficiente para entender probada la concreta difamación. La intención de difamar se encuentra muy por delante de la pretensión de influir en la opinión pública creando un estado de opinión sobre las fuerzas armadas. El Tribunal Superior confirma la sentencia. El recurso de amparo se fundamenta en la incorrecta interpretación realizada a lo expresado en la carta al director cuya pretensión era incidir en la opinión pública.

El cuarto recurso trae causa de lo acontecido en el pabellón olímpico de Munich con motivo de una exposición de motocicletas. En el pabellón de información de las Fuerzas Armadas alemanas (Bundeswehr) irrumpieron seis personas portando octavillas contrarias al ejército y una pancarta en la que se podía leer Soldaten sind potentielle Mörder (los soldados son potenciales asesinos). El Tribunal de primera instancia condenó a uno de los portadores de la pancarta por difamación. El Tribunal Superior confirmó la 
sentencia y el Tribunal Supremo del Land hizo lo propio. El recurso de amparo se fundamenta en la vulneración de los artículos 5.1 y $2.1 \mathrm{LF}$.

En fin, la condena que sufren por difamación los cuatro recurrentes hace que acudan al Tribunal Constitucional germano alegando la vulneración de su libertad de expresión reconocida en el artículo 5 de la Ley Fundamental; también entienden vulnerado con esta condena el artículo 103.2 LF ${ }^{15}$. Tras explicar el Bundesverfassungsgericht cómo debe entenderse la libertad de expresión y aclarar cómo su protección no depende de la mayor racionalidad o irracionalidad de las opiniones vertidas o de su mayor o menor fundamentación ${ }^{16}$, atiende al valor cualificado que adquiere la libertad de expresión en un Estado democrático.

Para Dieter Grimm, ponente de la sentencia, y catedrático de Derecho Público (Öffentliches Recht) jubilado de la Universidad Humboldt de Berlín, la libertad de expresión encuentra su límite en la protección del honor individual de la persona afectada. Pero esto no puede otorgar al legislador la potestad de limitar esta libertad de forma arbitraria; debe evitarse una limitación desproporcionada. En concreto, el apartado primero del artículo 5 de la Ley Fundamental prohíbe una interpretación del correspondiente precepto del Código Penal (artículo $185 \mathrm{StGB}$ ) que pueda producir un efecto espantoso o intimidatorio para el ejercicio del derecho fundamental; esto conduciría a coartar el legítimo ejercicio de la libertad de expresión por miedo a las posibles sanciones ${ }^{17}$. En opinión de Grimm, la medida para juzgar la limitación del derecho fundamental debe radicar en que con ella no sufra el principio democrático. Así se producirá si tal limitación produce un «chilling effect» (en terminología del Tribunal Supremo norteamericano) o un «einschüchternde Wirkung» como manifiesta el Bundesverfassungsgericht; en definitiva, un efecto desaliento o desmotivador en el ejercicio de los derechos fundamentales.

El Tribunal entiende además que goza de competencia para interpretar no sólo la ley penal sino las propias formulaciones de los recurrentes ${ }^{18}$. Opina

15 Este precepto obliga a la ley penal a determinar el delito con anterioridad a que éste se produzca. El Bundesverfassungsgericht entiende que la indeterminación alegada no se da. El concepto de ofensa ha sido expuesto en jurisprudencia constante de este tribunal y así los tribunales inferiores disponían de parámetros que ofrecían seguridad para aplicar el delito, BVerfGE 96, 266, 291, 292.

${ }_{16}$ BVerfGE 93, 266, 289.

17 BVerfGE 93, 266, 292. GrIMM, D., Die Meinungsfreiheit in der Rechtssprechung des Bundesverfassungsgerichts», Neue Juristische Wochenschrift, 1995, p. 1703.

18 BVerfGE 93, 266, 292 Así lo vuelve a defender GRIMM, D., Die Meinungsfreiheit in der Rechtssprechung des Bundesverfassungsgerichts», Neue Juristische Wochenschrift, 1995, p. 1700. Opinión distinta defiende HASS en el voto particular discrepante a esta sentencia. Opina que las especificidades del recurso de amparo impiden al tribunal 
que una interpretación como la realizada por los tribunales que condena a los recurrentes encierra el peligro de perjudicar el ejercicio del derecho fundamental a la libertad de expresión ${ }^{19}$. Por lo demás, lo determinante para interpretar lo manifestado por los recurrentes no es ni su pretensión subjetiva, ni el entendimiento subjetivo que tales expresiones puedan causar a los directamente aludidos, sino el significado que tiene para el público corriente ${ }^{20}$. En este sentido, se debe evitar una interpretación limitada al significado literal de las palabras; hay que acudir al significado contextual. Lo que viene exigido con mayor intensidad cuando se está juzgando la adecuación de la actividad penal ${ }^{21}$. Es decisivo, en definitiva, discernir si las opiniones manifestadas tienen como objetivo principal incidir en el foro público, promoviendo o fomentando una determinada sensibilidad, o la finalidad primera es ofender personalmente al denunciante.

En el caso en cuestión el derecho al honor no puede considerarse vulnerado, prevalece a la supuesta intención de ofender, la pretensión de incidir en el foro público. La difamación únicamente adquiere en principio relevancia constitucional cuando ocupa un primer plano en las declaraciones juzgadas. Sólo cabe una excepción a esta regla general: cuando aquélla se refiere contra grupos cuyo rasgo identificatorio es étnico, racial o corporal ${ }^{22}$.

\section{A MODO DE CONCLUSIONES}

Ya nos decía Habermas cómo el grado de vitalidad de una democracia se mide por el papel que desempeñan la deliberación, la reflexión y el espíritu crítico en la marcha de los asuntos públicos ${ }^{23}$. Y nos hacía tomar conciencia de cómo sólo una ciudadanía activa y beligerante puede ser el mejor remedio como control sobre los detentadores ocasionales del poder. El control del poder necesita pues de tal ciudadanía activa y de las mayores posibilidades de acción sobre el mismo.

Es cierto que la existencia de tal ciudadanía excede de las posibilidades del Derecho. Parece innecesario recordar lo que ya de Otto nos decía sobre la conocida «ilusión de los juristas». Como es también de sobra conocido, y nos

interpretar ni el Derecho positivo infraconstitucional, ni los hechos objeto de condena, BVerfGE 93, 266, 313.

19 BVerGE 93, 266, 295.

20 BVerfGE 93, 266, 295.

${ }^{21}$ BVerfG 93, 266, 296.

22 BVerfGE 93, 266, 304 vid, GRIMM, D., Die Meinungsfreiheit in der Rechtssprechung des Bundesverfassungsgerichts», Neue Juristische Wochenschrift, 1995, p. 1703.

${ }^{23}$ Habermas, J., Problemas de legitimación en el capitalismo tardio, Buenos Aires, Amorrortu, 1975. 
lo ha recordado Hesse, el Derecho constitucional precisa de ciertas condiciones materiales que lo hagan posible, son las denominadas garantías inmanentes ${ }^{24}$. Pero al margen de ello, no es menos cierto que el Derecho y en concreto el Derecho constitucional puede crear márgenes y estructuras que permitan y favorezcan la generación de tal ciudadanía. Y la emergencia de regulaciones que fomenten la subsunción de cualquier manifestación o expresión de odio en un tipo penal parece que no se orienta en la dirección correcta a tales fines.

Alertaba ya Raúl Morodo en 1987, en el contexto de unas manifestaciones estudiantiles, cómo «la proyectada democracia avanzada, inserta con optimismo constituyente en el preámbulo de la Constitución, se está deslizando gradualmente hacia una democracia reducida $\rangle^{25}$. Lo hacía a los efectos de criticar la reducción del Parlamento, proyectada en un sistema electoral injusto (pensado para viabilizar la transición política, pero que entonces ya debía en su opinión ser reformado), una regulación parlamentaria también injusta que privilegiaba -y sigue privilegiando- de forma desproporcionada al grupo parlamentario, y en unos partidos políticos carentes de democracia interna. Abogaba ya entonces por una democracia que, merced a las reformas propuestas, fuera más dialogante y avanzada. La falta de dinamismo interno, de crítica, pero también de posibilidades de expresión ideológica, eran manifiestas.

En cualquier caso, y siguiendo de nuevo a Hesse, no podemos olvidar que la Constitución sólo puede entenderse como Constitución de un concreto y determinado orden constitucional ${ }^{26}$. Y que tal orden constitucional puede tener unas particulares características que lo singularicen y en su caso den márgenes para extender ciertas limitaciones a la libertad de expresión. Las circunstancias sociales, políticas e incluso religiosas pueden mover a ello. Ahora bien, no podemos olvidar tampoco cómo la normatividad de la Constitución se defiende precisamente en los tiempos de crisis; lo resaltó también $\mathrm{Hesse}^{27}$. Y que la libertad de expresión, directamente conectada con el valor del pluralismo político y social, es un derecho básico y medular de nuestra vigente democracia constitucional.

Es cierto que la frontera entre la legítima acción verbal contra un colectivo, de un lado, y el acoso y la coacción personal e individualizada, del otro,

${ }^{24}$ Hesse, K., «Constitución y Derecho constitucional», Benda, E.; MAIHOFER, W.; Vogel, H.; Hesse, K.; Heyde, W., op. cit, pp. 8, 9.

${ }^{25}$ Morodo Leoncio, R., «Salir de la democracia reducida», El País, 7 de febrero de 1987.

${ }^{26}$ Hesse, K., Escritos de Derecho constitucional, Madrid: Centro de Estudios Constitucionales, 1992 , pp. 3, 4 .

${ }^{27}$ Hesse, K., Escritos de Derecho constitucional, Madrid: Centro de Estudios Constitucionales, 1992, p. 71. 
es muy tenue. Lo primero parece que podría gozar de amparo en un Estado democrático, toda vez que tiene como finalidad primera incidir en el foro público, generar opinión pública. Lo segundo podría no tener lugar en tal Estado democrático, pues procura simplemente amedrentar al acosado mediante la coacción a él o a su familia. Grimm usa esta distinción para otorgar mayores garantías a la libertad de expresión, sobre todo para evitar el efecto desaliento que en el ejercicio de tal derecho puede provocar una penalización desproporcionada de cualquier manifestación polémica. Pero Blanco Valdés, por ejemplo, también hace uso de esta diferencia para condenar los denominados escraches, no considerándoles amparados por la libertad de expresión: por qué denominar escrache a lo que supone a todas luces un acto de coacción, se plantea ${ }^{28}$.

De nuevo, el problema podría consistir en no convertir necesariamente cualquier ejercicio de la libertad de expresión y en este caso de manifestación en un acto de acoso personal e individualizado. Puede haber casos en que el acoso sea real y prevalezca al intento de incidir de forma pacífica en el foro público, pero puede haber otros muchos supuestos en que tal circunstancia no tenga necesariamente que ser así. Por ejemplo, el Auto de la Sección Decimosexta de la Audiencia Provincial de Madrid del 29 de mayo de 2015 podría hacernos ver los peligros de caer en tal extensión: el mencionado Auto desestima el recurso del Ministerio Público que solicitaba la condena a los promotores de la manifestación convocada por la Plataforma de Afectados por la Hipoteca (PAH) ante la vivienda de la Vicepresidenta del Gobierno, Soraya Sáez de Santamaría, al entender que era constitutiva de un delito de coacciones no amparable por la libertad de expresión y el derecho de reunión. Tal delito de coacciones se proyectaría en primer lugar en la incidencia en la libertad de obrar del denunciante, que según manifestó tuvo que abstenerse de salir a pasear con su hijo; pero en segundo lugar, existe en su opinión una pretensión de restringir la libertad de obrar de la Vicepresidenta en su faceta política. La concentración frente al domicilio de la Vicepresidenta del Gobierno duró en torno a 20 minutos y se profireron gritos como «sí se puede, pero no quieren», «Soraya, Soraya, quien te paga tu casa», «no son suicidios, son asesinatos».

En opinión de la Audiencia, sin embargo, la manifestación realizada tuvo efecto dentro del marco amparado por nuestra Constitución. En el caso en cuestión, no concurrieron personas con armas, explosivos ni objetos contundentes; y tampoco se acreditó que la protesta se convocara para cometer delito de coacción o atentado. El Tribunal no aprecia delito de coacciones; en

${ }^{28}$ Blanco ValdÉs, R., «¿Escraches? No, gracias», Claves de razón Práctica n. ${ }^{\circ} 229$, 2013, p. 62. 
primer lugar, sobre la libertad de obrar del denunciante ${ }^{29}$, pues tal incidencia en la libertad de obrar no se ejerció directa ni indirectamente sobre el denunciante mediante violencia física o fuerza en las cosas. Pero tampoco aprecia una pretensión de restringir de forma violenta la libertad de obrar de la Vicepresidenta: «no se exterioriza que la finalidad perseguida sea la de quebrantar la voluntad política de la Vicepresidenta salvo que todo legítimo intento o deseo de influir en el criterio de otro sea considerado como tal» ${ }^{30}$.

Por lo demás, no se recogen ni se refieren por los denunciantes en ningún momento actos o expresiones por parte de los denunciados que pudieran ser indicativos de la intención de causar algún perjuicio a la Vicepresidenta del Gobierno. Para el Tribunal, en fin, y según consta en los vídeos policiales aportados a la causa, «las frases empleadas, los gritos proferidos o los carteles que portaban los manifestantes denunciaban la decisión política del PP de votar en contra de la iniciativa legislativa popular auspiciada por la plataforma en materia de deshaucios y pretendían informar a la opinión pública sobre ello e incluso algunos manifestaban el deseo de mantener un diálogo con la vicepresidenta al respecto. No portaban armas, no emplearon violencia sobre las personas, no emplearon fuerza en las cosas y la perturbación del orden inherente a estas concentraciones numerosas no se saldó con daños a objetos o bienes de terceros, ni acometimiento alguno a las fuerzas policiales ni a otras personas $\rangle^{31}$.

Desde una óptica parcialmente distinta, pero coincidente en muchos aspectos, Savater acudía en una reciente publicación en defensa de la libertad de expresión religiosa. En el número 240 de la Revista Claves de Razón Práctica de mayo/junio de 2015 decía el filósofo y escritor que vivimos en una época peligrosa para los blasfemos; incidía en algo que parece de suma importancia: «Ofender con palabras o gestos la fe ajena puede ser una muestra de libertad de expresión, o una manifestación artística o incluso una forma de religión distinta (no olvidemos que Cristo fue crucificado por blasfemo). También podemos considerar que es algo descortés y grosero, una falta de respeto y de delicadeza hacia el prójimo. En cualquier caso, dentro del pluralismo y la libertad de conciencia de una sociedad democrática, lo único evidente es que no se trata de un crimen $»^{32}$; la discusión, opina, se centra «en si

${ }^{29}$ La indudable restricción a la libertad de obrar que supuso impedir -más bien desalentar, porque no llegó a intentarlo- que saliera a pasear con su hijo, por la presencia de tantas personas manifestándose no se ejerció mediante violencia física ni fuerza en las cosas, Auto de la Audiencia Provincial de Madrid de la Sección 16. ${ }^{a}$ n. ${ }^{\circ} 81 / 14$, FJ 3.

${ }^{30}$ Auto de la Audiencia Provincial de Madrid de la Sección 16. ${ }^{\mathrm{a}}$ n. ${ }^{\circ} 81 / 14$, FJ 3.

31 Auto de la Audiencia Provincial de Madrid de la Sección 16. ${ }^{a}$ n. ${ }^{\circ} 81 / 14$, FJ 3.

32 Savater, F., «Vivimos una época peligrosa para los blasfemos», Claves de razón Práctica n. $^{\circ} 240,2015$, p. 5. 
debemos evitar por prudencia y en pro de la buena armonía cívica aquellas expresiones cáusticas o hirientes que los fieles pueden tomar como blasfemias (es decir, como agresiones a lo por ellos más apreciado) o si la libertad de irreverencia es el reverso necesario a la libertad de adoración en el marco institucionalmente laico de nuestra convivencia» ${ }^{33}$.

Las respuestas, en definitiva, no son fáciles; aunque en caso de duda parece que siempre debería estarse a la mayor extensión en las garantías de la libertad de expresión; in dubio, pro libertate. Seguramente estaríamos así haciendo el mejor favor al mantenimiento de la democracia avanzada y en libertad de la que hablaba Raúl Morodo y de la que nos dotamos todos los españoles en 1978.

TITLE: Can all hate speech expressions constitute an imbridgeable limit on freedom of expression?

RESUMEN: Este artículo analiza algunos aspectos del complejo campo de uno de los conocidos limites a la libertad de expresión, la manifestación de expresiones de odio. Una primera aproximación al concepto de la libertad de expresión (1) nos permitirá centrarnos en el examen del mencionado límite (2); para, a continuación, exponer las garantías de esta libertad central de nuestro vigente constitucionalismo. Procuraremos alcanzar ciertas conclusiones que quizá puedan orientar la mejor salvaguardia de la libertad en una democracia avanzada como la que proclama la Constitución de 1978 (4).

PALABRAS CLAVE: libertad de expresión, expresiones de odio, garantías, democracia avanzada.

ABSTRACT: This article discusses some aspects of the complex field of one of the known limits to freedom of expression, the manifestation of hate speech. A first approach to the concept of freedom of expression (1) will allow us to focus on the examination of that limit (2); to then expose this central guarantees freedom of our current constitutionalism. Pursue certain conclusions that may be able to guide the best safeguard of freedom in an advanced democracy as proclaimed by the 1978 Constitution (4).

KEY WORDS: Freedom of expression, hate speech, guarantees, advanced democracy.

RECIBIDO: 07.04.2016

ACEPTADO: 22.06.2016

33 SAVATER, F., «Vivimos una época peligrosa para los blasfemos», Claves de razón Práctica n. $^{\circ} 240,2015$, p. 5. 